\title{
Interview
}

\section{Creativity and Marketing: Interview With Marie Taillard}

\author{
Marie Taillard ${ }^{\mathrm{a}}$, Vlad Glăveanu*b \\ [a] Creativity Marketing Centre, ESCP Europe - London Campus, London, United Kingdom. [b] EJOP Editor; Aalborg University, Aalborg, \\ Denmark.
}

\begin{abstract}
In this interview Dr. Taillard discusses her interest and ongoing research in the areas of marketing, consumer behaviour and creativity. She considers how academic training can be applied to a business context and describes the newly formed Creativity Marketing Centre at ESCP Europe. Exploring the multiple intersections between creativity and marketing represents not only a paradigmatic change for those interested in business and consumer behaviour but also for researchers of creativity who can start envisioning and studying consumption as a creative act. This interview will offer valuable points of reflection for all those interested to know more about this approach.
\end{abstract}

Europe's Journal of Psychology, 2012, Vol. 8(4), 519-522, doi:10.5964/ejop.v8i4.556

Received: 2012-11-20. Accepted: 2012-11-20. Published: 2012-11-30.

*Corresponding author at: Department of Communication \& Psychology, Aalborg University, Kroghstræde 3, 9220 Aalborg, Denmark, email: psy.journal@gmail.com

This is an open access article distributed under the terms of the Creative Commons Attribution License

(http://creativecommons.org/licenses/by/3.0), which permits unrestricted use, distribution, and reproduction in any medium, provided the original work is properly cited.

Vlad Glăveanu: Dr. Taillard, you have been trained both in business and linguistics and currently specialise in marketing management and consumer behaviour. What exactly brings these interests together and how can knowledge of linguistics help understand both consumers and firms?

Marie Taillard: Thanks for picking up on my fairly atypical background. You're right, I have a Ph.D in Linguistics as well as an MBA (with a Finance concentration), and extensive experience in services marketing. To me what links all this together is a passion for the mechanisms and substance of social interactions, and in particular communication. The area of linguistics in which I pursued my research is pragmatics, at the intersection of linguistics, cognitive psychology, anthropology and philosophy of language. In my Ph.D thesis, I explored persuasive communication phenomena, both from the persuader's and the audience's perspectives. The theoretical framework in which I anchored my research is Relevance Theory, developed by Dan Sperber and Deirdre Wilson, my supervisor. I also looked at the evolutionary roots of persuasion, which I showed are clearly linked to factors of influence such as authority, scarcity, commitment, reciprocity and such, documented by Robert Cialdini, but also in the cultural transmission literature by Rob Boyd and some of his colleagues. In other words, persuasion works because it appeals to adaptive tendencies humans have to be influenced by certain types of individuals (e.g., in positions of authority), under certain circumstances (e.g., under scarcity), using certain types of appeals (e.g., reciprocity or commitment). I applied some of this research to my experience as a marketer - trying to understand persuasion in marketing, from both the firm's and the consumer's angles. In the meantime, digital marketing and social media were developing fast and opened up all sorts of interesting opportunities to think about communication and persuasion. Should we consider social media a more sophisticated persuasive strategy (the next level in a persuasion arms race), in which persuasive intent is much less manifest than in more traditional media? 
Vlad Glăveanu: One particular focus of your research relates to the role of the Internet in facilitating communication within organisations and also among consumers. What exactly is specific to this medium of communication and exchange that can shape the behaviour of stakeholders and consumers and foster value generation processes?

Marie Taillard: The interesting thing about the Internet as far as marketing is concerned, is that it takes away much (not all) of the traditional information asymmetry between producers and consumers. It shifts control back to consumers, and allows them to exchange information with each other, and to act publicly, either individually or collectively in relation to the brand. Whether they "like" a brand on Facebook, post a negative review on TripAdvisor, contribute a recipe on Epicurious.com, or participate in a tweetchat, they contribute to the brands they consume in creative ways and add value both to their own experience of the brand, and as a a result, to the brand itself (they can also take value out of the brand if they complain publicly). So, there are more and more opportunities for consumers to take some of their consumption experience online and in so doing to create value around the brand. You mention other stakeholders - the argument is the same - employees, suppliers, retailers and such all have similar opportunities, sometimes through specific channels (e.g., a retailer can promote the brand on their own site, thus creating more value for themselves along the way).

Vlad Glăveanu: At a methodological level, what can an analysis of conversations (including discussions in online forums) tell us about consumer behaviour and consumer creativity?

Marie Taillard: Well, I see these forums as veritable petri dishes of creativity! Individuals are interacting spontaneously out of sheer interest or passion, sharing, solving problems, creating new practices. We are using conversation analysis as a methodology as it allows us to see how conversations build into creative outcomes one contribution at a time. It is the very structure of conversation, the exercise that consists in crafting a contribution and interpreting others', and so on, which allows greater creativity to emerge. We have never before had access to this level of spontaneous and transparent dialogue. Of course, we must be aware of and sensitive to ethical concerns of confidentiality and disclosure, but the insights we can gain, are nothing short of phenomenal.

Vlad Glăveanu: You are currently directing the Master in Marketing and Creativity launched in 2009 at ESCP Europe. This represents a rather unique combination of these two areas, what would you say are the overlaps between marketing and creativity?

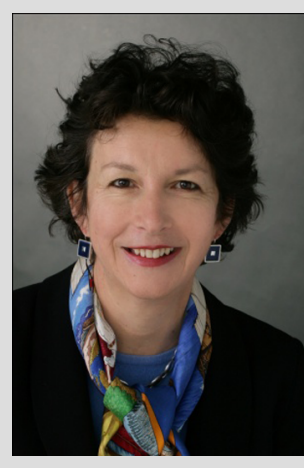

Marie Taillard earned her MBA from Columbia Business School and her Ph.D. from the University of London. Her previous academic work was in Linguistics and she specializes in studying marketing management and consumer behavior from the perspective of the communications that take place between consumers and firms and amongst consumers themselves. She is interested in how the internet has transformed relationships between stakeholders in organizations and in how consumers contribute to creating value with companies. She has also conducted research in the area of change management. Dr. Taillard held management positions in the United States for American Express, Council Travel, UTA French Airlines, Club Med and Accor Hotels. Marie Taillard is a member of the American Marketing Association, the Academy of Marketing Science and the Association for Consumer Research. As a member of ESCP Europe's Permanent Faculty since 2007, she teaches in several postgraduate and executive programmes at the School. She is the Academic Director of the School's successful Master in Marketing and Creativity whose launch she spearheaded in 2009. She is expanding her research in Marketing and Creativity as the Director of the new Creativity Marketing Centre on the London Campus of ESCP Europe. Correspondence: ESCP Europe London Campus, 527 Finchley Road, London NW3 7BG, United Kingdom, email: mtaillard@escpeurope.eu 
Marie Taillard: It is a unique combination, you are quite right. There have always been overlaps between the two areas. Advertising agencies have creative staff - the people who come up with the creative elements of a campaign, whether it is copy for print ads, slogans, the "big idea" (and smaller ones too) behind a commercial etc. What we are developing and teaching is creativity at a much broader and strategic level. Our premise is that marketing is evolving very fast, competition is increasing and consumers are increasingly confused about the benefits of one brand vs. another. This is the context that requires what we call "creativity marketing" - starting with a thorough understanding of consumers, allowing consumers (and all other stakeholders) to deploy their own creativity at every possible touch point. Consumption is packed with creativity through and through: consumers take a product or service and make it their own. The same is true for other relationships between brands and their stakeholders (employees - particularly in service industries, suppliers, distributors etc.). So creativity marketing is about focusing on these relationships and the creative opportunities to create value for all involved. At the same time, we also advocate a stronger balance between the creative and analytical sides of marketing. The digital context has enabled the capture and storage of unprecedented amounts of valuable data ("big data"), which can and should be analyzed for greater insights and more efficient management. These analytical processes too present excellent opportunities for creative thinking. The most sophisticated algorithms cannot begin to compete with human creativity in asking incisive questions, drawing insights from statistical patterns and telling compelling stories from these data. We are so convinced of the importance of these overlaps that we are actually "branding" this a new perspective on marketing, "creativity marketing", and teaching it successfully to students from around the world.

Vlad Glăveanu: What kinds of skills are developed within this programme and what type of jobs do graduates usually aim for after completing their studies?

Marie Taillard: The program is based on three pillars, creativity, marketing and management skills. We want to make sure that our graduates hone their creative skills so as to apply them to a better understanding of consumers, of markets, of value creation processes and opportunities, and of their role within organizations. That and a good dose of analytical skills. Beyond skills, we also help students develop a managerial mindset - creativity has a role to play there too.

Vlad Glăveanu: You are also directing the newly formed Creativity Marketing Centre $(C M C)$ at the London Campus of ESCP Europe. What kinds of research projects are specific to this centre?

Marie Taillard: You are right, we are at the very beginning of the life of the Centre, and are developing a number of projects - we have one going on around creativity and value creation, another focused on consumer creativity - working with data from consumer forums, one around big data and creativity and another new one in partnership with a large multinational company on creativity in the "brand ecosystem". A number of researchers in marketing, consumer behaviour, organizational behaviour, psychology and anthropology have agreed to work with us and so we are starting to formulate more projects to bring these disciplines to bear on our research.

Vlad Glăveanu: How is creativity conceptualised by members of the CMC and what are the implications of this "definition" for our understanding of marketing and consumer behaviour in particular?

Marie Taillard: I think that our roots in the social sciences naturally make us inclined to think of creativity as a social or cultural phenomenon. In your own recent papers, for instance, you develop a very interesting socio-cultural perspective on creativity in which audiences and affordances are part of the process of actors performing creative acts resulting in creative artefacts. This type of characterization is particularly in line with our perspectives on 
creativity and consumption - consumption is a personal experience, but one that is also deeply social and cultural at the core.

Vlad Glăveanu: Conversely, what can studies of consumer behaviour tell us about creativity as a phenomenon and its current forms of expression?

Marie Taillard: This is one aspect we have yet to explore, but I would think that looking at creativity in the context of consumption should give us access to a whole new range of data from which to gain better insights into creativity. In particular I see opportunities to tap into a veritable treasure trove of examples of creativity at work, for instance among consumers participating in online conversations as part of their consumption experiences.

Vlad Glăveanu: What do you think are the greatest challenges faced today by people working in the area of creativity and marketing and how can they be addressed by practitioners?

Marie Taillard: To tell you the truth, I think we are now in a situation where the opportunities far outweigh the challenges. This is a very exciting time for marketers - we have lots of engaged and informed consumers and powerful ways to communicate with them and enable further engagement. Thanks to this and the ongoing dialogue we can develop, we can bring consumers into the value creation loop, and as a result, create new paradigms for value creation. This is very important in face of the growing sense of discomfort experienced by consumers, which we as consumers ourselves can certainly identify with, particularly in the context of the severe global economic crisis. As marketers, we can no longer feel satisfied with pushing consumption for consumption's sake. We must adopt a much more collaborative attitude to our practice of marketing.

Vlad Glăveanu: Finally, what would be a word of advice for young scholars interested in studying the creativity of consumption or working towards building a career in marketing?

Marie Taillard: The key words in my mind are creativity, empathy (i.e., being able to relate to consumers' needs, emotions etc.), dynamism (adapting to constant change) and rigor (in analyzing markets, consumers, opportunities etc.). Certainly, these skills and attitudes are those with which we try to equip our students, and this is what I think will help them excel in the future. It's above all a very human and social field where having a real passion for how humans go about conducting their daily lives as social beings is crucial.

Vlad Glăveanu: Thank you very much for sharing your thoughts with us. 